\title{
PROPUESTAS DE ANÁLISIS CONSERVATIVO NO MATERIAL O MATERIAL EN CASOS DE ESPECIAL SIGNIFICACIÓN EN ARTE Y MURALISMO URBANO: JAÉN Y BELIN
}

\section{Carmen Moral Ruiz}

Universidad de Huelva. Dpto. Didácticas Integradas

\section{Laura Luque Rodrigo}

Universidad de Jaén. Dpto. Patrimonio Histórico

\section{Resumen}

La conservación de las manifestaciones artísticas que se presentan dentro del espacio urbano es compleja ya que son de carácter muy diverso. Este tipo de manifestaciones pueden estar vinculadas con diversas áreas, como, por ejemplo, la arquitectura, la escultura o la pintura en sus diversas concepciones. A su vez, cuentan con una variedad matérica muy amplia y una problemática de conservación al encontrarse, normalmente, en exteriores sin vigilancia y expuestas a la intemperie. A lo largo de esta aportación, se pretende establecer una metodología de documentación y estudio de estas obras a través de casos particulares de obras ubicadas en Jaén, en concreto del artista urbano Belin, de forma que se establezca un marco de actuación en el que tengan cabida diversas casuísticas de conservación asociadas a estas manifestaciones.

Palabras clave: CONSERVACIÓN; DOCUMENTACIÓN; ARTE URBANO; MURALISMO; BELIN (MIGUEL ÁNGEL BELINCHÓN BUJES, 1979-); JAÉN (PROVINCIA)

\section{PROPOSALS FOR NON-MATERIAL OR MATERIAL CONSERVATION ANALYSIS IN CASES OF SPECIAL SIGNIFICANCE IN URBAN ART AND MURALISM: JAÉN AND BELIN}

\section{Abstract}

The conservation of the artistic manifestations that are presented within the urban space is complex, as they are of a very diverse nature. This type of manifestation can be linked to different areas, such as: architecture, sculpture or painting in its different conceptions. At the same time, they have a wide variety of materials and conservation problems, as they are usually located outdoors, unattended and exposed to the elements. The aim of this contribution is to establish a methodology for documenting and studying these works through particular cases of works located in Jaén, specifically by the urban artist Belin. In so doing, the intention is elaborate a framework for action in which various conservation cases associated with these manifestations.

Keywords: CONSERVATION; DOCUMENTATION; URBAN ART; MURALISM; BELIN (MIGUEL ÁNGEL BELINCHÓN BUJES, 1979-); JAÉN (PROVINCE, SPAIN)

Moral Ruiz; Laura \& Carmen Luque Rodrigo. 2021. "Propuestas de análisis conservativo no material o material en casos de especial significación en arte y muralismo urbano: Jaén y Belin". AusArt 9 (2): 47-64. DOI: 10.1387/ausart. 23081

\section{AUSART}




\section{INTRODUCCIÓN}

Dentro del espacio urbano se reúnen distintos tipos de expresiones artísticas, desde aquellas puramente arquitectónicas y monumentales a obras que desde su origen se conciben con otras finalidades. Es el caso del graffiti ${ }^{1}$, manifestación que no es definida como arte, pero que es de gran interés en su dimensión antropológica y, a veces, incluso estética en algunas piezas, aunque el mayor interés recala en su idea de apropiación de la ciudad. El graffiti contemporáneo no nace con idea de perdurar en el tiempo, el escritor de graffiti desea poner su firma en el mayor número de lugares posibles, es un juego que se desenvuelve en el presente, entre iguales, para escalar en la jerarquía que crean los propios escritores. Por otro lado, el arte urbano, el espontáneo, tampoco busca la inmortalidad. Son obras que dialogan con la ciudad, buscan integrarse en sus espacios, con un componente estético que puede pasar desapercibido incluso de las miradas de los transeúntes o causar impacto si se percibe. Ambos tipos de manifestaciones se entienden como efímeras. Por otro lado, la institucionalización del arte urbano, especialmente desde 2010, ha dado lugar a obras por encargo de muralismo monumental en el espacio público, en gran medida en el marco de festivales, pero no siempre con la pretensión de perdurar dado que los muros pueden ser reutilizados. Es decir, estos tres tipos de manifestaciones que tienen cosas en común, como el uso del espacio público, no se crean con la idea de perdurabilidad².

A lo largo de esta aportación, se toma en consideración que el propio concepto de graffiti, de arte urbano y en gran medida de nuevo muralismo o muralismo público, impide a priori que los profesionales de la conservación-restauración trabajen en proyectos de intervención que alarguen la vida de las obras. Sin embargo, esto no implica, como se verá más adelante en las propuestas sobre obras de Belin (Linares, Jaén), que no se preserve su memoria de forma no material o que, a veces, sea necesario intervenir para alargar la vida de una obra. Rava y Collina (2018) indican en la introducción del monográfico que la revista Kermes dedicó a la conservación del arte urbano, que es un tema contradictorio en sí mismo que suscita polémica entre los artistas y que debe ser tratado por los especialistas con sumo cuidado, atendiendo a los casos en que las obras se han convertido en iconos sociales. Por ejemplo, el graffiti del Muelle de la Calle Montera de Madrid (García 2017) fue intervenido bajo el paraguas del BICOMUN (Niquelarte $2013^{3}$ ) que se recoge dentro del código deontológico del Grupo de Arte Urbano y Público del International Institute for Conservation (García et al. 2016) por ser un caso de especial significación. 
En cualquier caso, las tareas de catalogación son primordiales, la base para el conocimiento, para una posible intervención, para la divulgación y para preservar la memoria de forma no material (Bengtsen 2021). Este trabajo presenta algunos de los resultados obtenidos en el Proyecto de Investigación Pintado en la pared. Estudio de la pintura sobre muro en la provincia de Jaén en los siglos $X X-X X I$, financiado por el Instituto de Estudios Giennenses y desarrollado entre diciembre de 2020 y noviembre de 2021. El marco de este proyecto nos ha permitido realizar un estudio de las obras de arte urbano y de grafiti de la provincia desde un punto de vista teórico, mediante la recopilación bibliográfica, estudio de las obras in situ, entrevistas a artistas, etc. aunque no nos ha permitido el estudio material de las obras o intervenciones en las mismas.

\section{ANÁLISIS DE CONSERVACIÓN DE OBRAS EN LA PROVINCIA DE JAÉN}

El análisis de conservación de obras se ha realizado a través del citado proyecto que ha dado como resultado la realización de la ficha de catalogación. Dicha ficha se ha basado en la elaborada previamente por María Isabel Úbeda (2016), presentando como novedad la importancia de la significación y, sobre todo, el hecho de poder probarlas en una cantidad considerable de obras, -más de 500-. Los apartados han sido los siguientes: nombre, autoría, fecha de ejecución, localización con georreferenciación, naturaleza material, técnica y formal, iconografía y temática, bibliografía, documentación fotográfica, etc. Para alguno de estos apartados se han elaborado tesauros, como el caso del estado de conservación para el que se ha elaborado un tesauro específico referente a alteraciones de los materiales que componen las obras y que se basan en los recogidos en el Proyecto COREMANS (Ministerio de Cultura y Deporte $\left.{ }^{4}\right)$, los del Proyecto CAPuS $\left(2020^{5}\right)$ y otros especializados en determinados materiales como el de materiales pétreos elaborado por ICOMOS-ISCS (2010). En dicho tesauro se distinguen entre las alteraciones derivadas del estado del soporte y las de la capa pictórica, incidiendo en la importancia de preparación del soporte, ya que muchos daños ya estaban presentes en obras subyacentes sobre las que se ejecutaban las estudiadas. A su vez, se llama la atención sobre la variedad de materiales presentes en los soportes del arte urbano: plásticos, metales, maderas, materiales pétreos, etc. que ha conllevado la consideración de terminología específica. Por último, en esta ficha se recoge, si es posible, la entrevista al artista para conocer datos sobre 
la ejecución de la obra, y su intención en cuanto a su conservación y posible intervención, entre otros aspectos.

La aplicación práctica del análisis de las obras se ha realizado en creaciones de diversa tipología y con casuísticas muy diversas en cuanto a su concepción, materiales, etc. En el caso del grafiti, ya fueran potas, piezas o tags, no se realizaron fichas de catalogación como tal, ya que el interés radicaba en establecer pautas por barrios, vislumbrando qué firmas se repetían más, cuál era su grado de elaboración, qué crews existen, formatos, etc. En este caso no se estudió su conservación ya que son obras absolutamente efímeras, sólo se habría realizado si hubiese algún caso de especial significación.

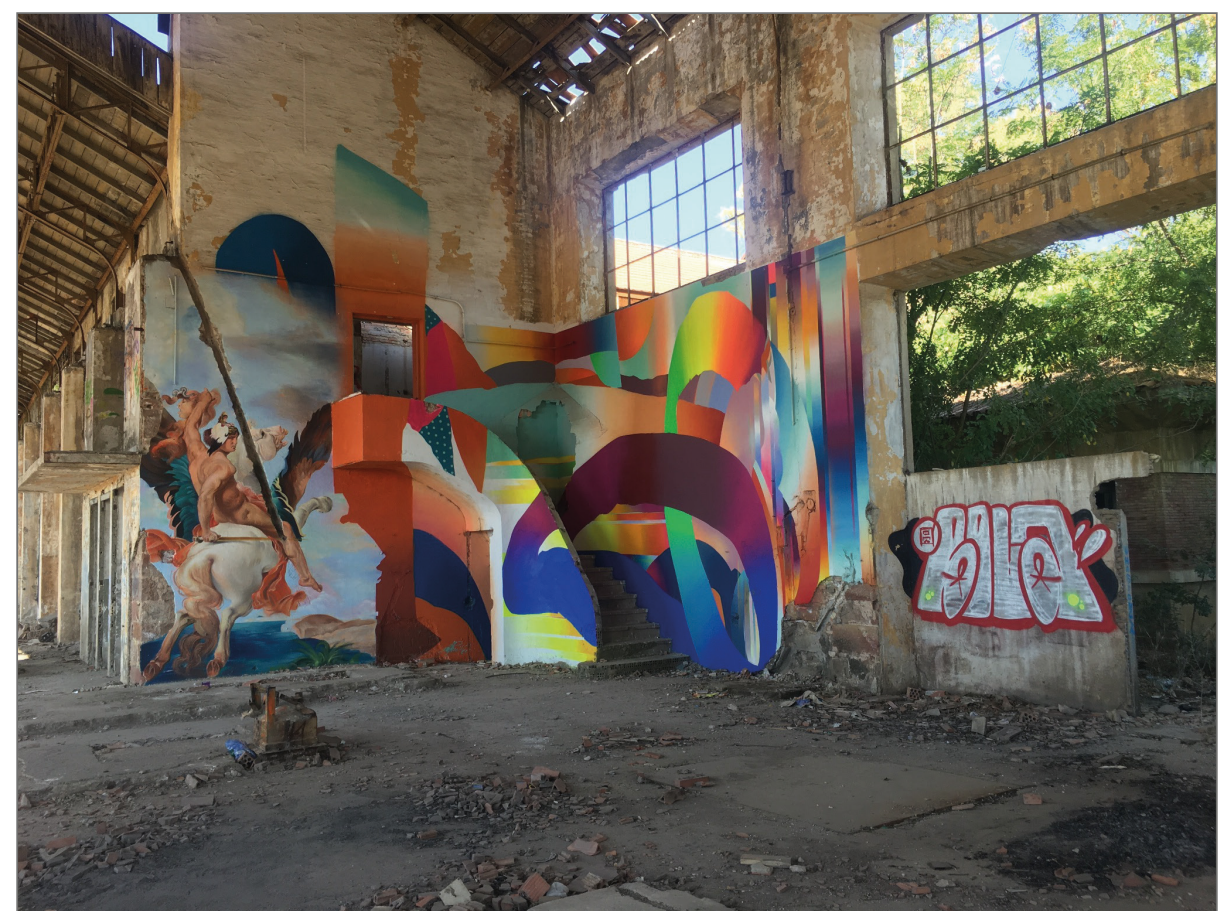

Figura 1. De dcha. a izq. pompa en plata y rojo; obra de arte urbano abstracta; obra de arte urbano que recrea la obra Perseo caballo Pegasus (1869) de Paul Joseph Blanc, que actualmente se encuentra en el Museo de Orsay de París. Fundición La Cruz (Linares). Fuente: imagen propia.

Entre las obras catalogadas de arte urbano, la mayoría de las alteraciones son fruto de la falta de preparación de los soportes, ya que muchas son espontáneas, dando lugar principalmente a desprendimientos y grietas. También presentan coloraciones negras por colonización biológica, alteración muy común 
en los revestimientos que se encuentran en la intemperie. Otra de las alteraciones más usuales se debe a la ejecución de obras sobre morteros de cemento, ya que al colocar capas que no permiten que el muro transpire se producen desprendimientos y la aparición de eflorescencias. Como ejemplo de las obras catalogadas se pueden citar las de la fundición La Cruz de Linares (Fig. 1 y 2), a las que haremos referencia más adelante, las cuales presentan un estado variable de conservación pero que, en general, sufren desprendimientos en diversos puntos por el mal estado de los soportes, así como colonización biológica de diversa tipología y entidad y depósitos.

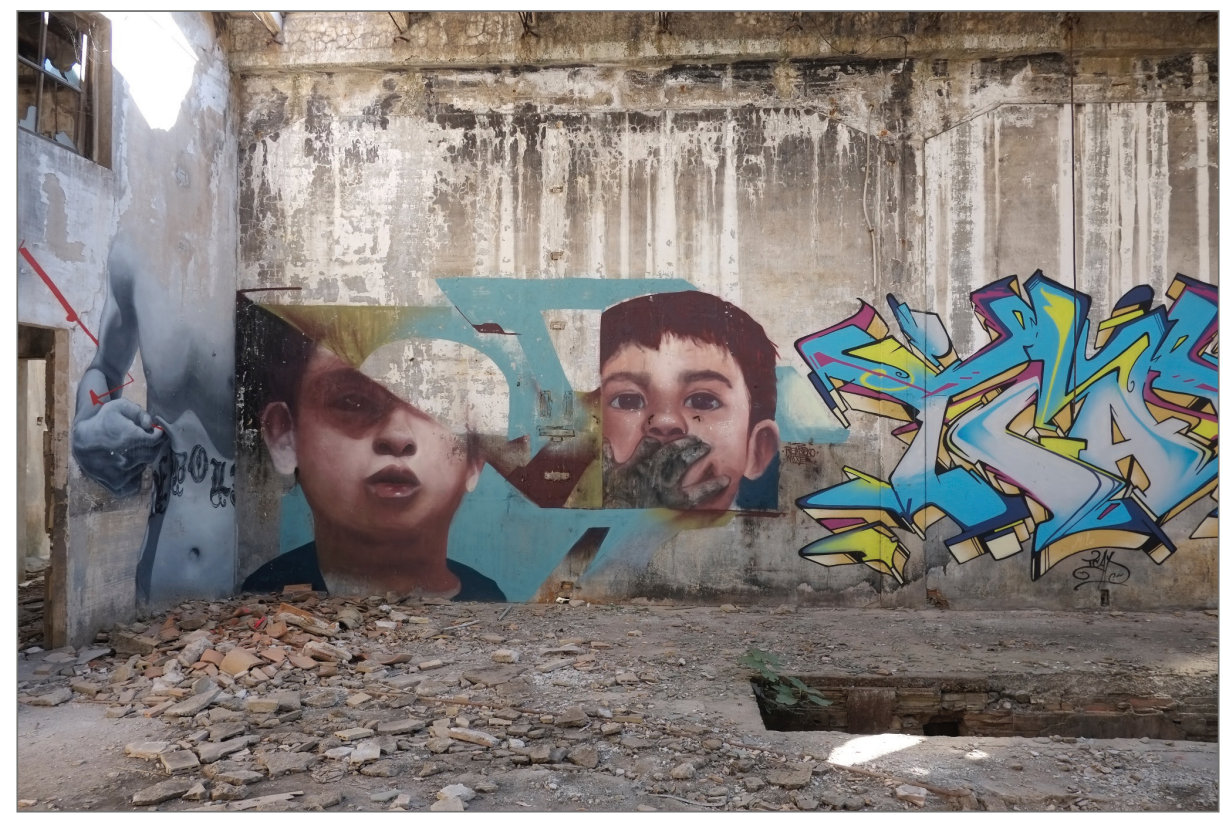

Figura 2. Arte urbano y grafiti en la Fundición La Cruz (Linares). Fuente: imagen propia.

\section{PROPUESTAS DE CONSERVACIÓN NO MATERIAL}

\subsection{La CATALOGACIÓN Y LA FOTOGRAMETRÍA COMO HERRAMIENTA PARA LA CONSERVACIÓN Y DIFUSIÓN}

La importancia de la catalogación implica el desarrollo de herramientas para la conservación y divulgación, destacando entre estos instrumentos la foto- 
grametría. A través de esta técnica obtenemos una imagen bidimensional o modelo tridimensional de calidad, con o sin el entorno y con datos en verdadera magnitud a través de la toma de imágenes en condiciones determinadas y la utilización de software específicos como es el caso del utilizado en esta aportación, Agisoft Photoscan. Estudios previos muestran resultados óptimos en el campo de la divulgación y la conservación, aunque no es una herramienta exenta de problemáticas por la incidencia del sol en las imágenes, objetos que impiden la visualización de las obras, etc. (Moral \& Luque 2021). En este sentido, se están abriendo nuevas vías de visualización y difusión de obras de arte urbano dentro de entornos museísticos virtuales mediante la virtualización 3D, como el caso de la exposición virtual de arte urbano Take III Loving Street Art Belgrade en Virtual Reality Exhibition (Street Art Belgrade $\left.2021^{6}\right)$. Estas prácticas podrían evitar actuaciones que inciden negativamente en la naturaleza de este tipo de manifestaciones, como arranques de muro para su exposición, exposición de obra gráfica y la intervención en muros interiores (veáse Revista Ge-Conservación, 20197).

\subsection{Conservación de hall of fame en Linares}

Una forma interesante de conservación no material podría ser mediante la preservación del muro para que pueda ser intervenido a lo largo del tiempo, práctica que ya se realiza en algunos festivales para el muralismo, pero en este caso abordado desde el compromiso institucional para no blanquear ciertos muros espontáneos. Esta práctica es definida como hall of fame para el graffiti, siendo también desarrollada por el arte urbano espontáneo. Lo que se preservaría en este caso, no son las obras materiales, sino el contexto inmaterial que genera el propio muro. En este caso, sería esencial la documentación de las obras para estudiar la evolución del fenómeno y preservar la imagen de cada obra que se haya ido superponiendo a la anterior, aunque implica un alto nivel de actualización ya que se irían solapando. Tal y como refiere Almirón (2021), en esta iniciativa habría que considerar los muros desde un punto de vista estratigráfico. Estos estarían conformados, según el autor, por "estratos urbanos" (Almirón 2021, 215) que podrían ser catalogados y documentados fotográficamente. Almirón (2021) llama la atención sobre la necesidad de incluir al colectivo de artistas en esta actualización de lo que sucede en el muro, aunque es complejo ya que suelen ser obras de gran espontaneidad y algunas veces anónimas.

Un caso interesante en este sentido es el de la fundición La Cruz, construida en 1830 a $5 \mathrm{~km}$ de Linares, área minera de la provincia de Jaén que se remonta 
a la Antigüedad. Esta fundición junto con la Compañía de Minas de la Cruz fueron las últimas en desaparecer, dejando un paisaje árido caracterizado por la altura de las chimeneas (Pérez 2018). Desde su cierre, como es habitual desde los inicios del graffiti y del arte urbano, ha servido de lienzo en blanco para escritores y artistas urbanos. Se suceden distintos tipos de firmas, potas y piezas y sobre todo, por influjo de Belin -de quien se tratará más adelante-, obras de arte urbano cada vez más elaboradas y superpuestas a otras, en las que se observa la evolución del grafiti y el arte urbano en Linares y, en concreto, de este artista, al ser uno de los que más piezas tiene, pues sigue interviniendo este símbolo de Linares a pesar de dedicarse al muralismo público. Belin cuenta en este muro con firmas en forma de pieza (Fig. 3), obras de tipo hiperrealista-surrealista del inicio de su carrera (Fig. 4), con estilo hiperrealista neocubista característico del periodo actual (Fig. 5) y pequeños dibujos cubistas de un solo color y trazo (Fig. 6). Se observa la progresión desde su firma sencilla de borde negro y relleno blanco al estilo del metro de NY de los años ' 70 , hasta su refinamiento artístico actual. Junto con la obra de Belin aparecen otros artistas reconocidos como Rallito X o Flaxt, entre otros muchos.

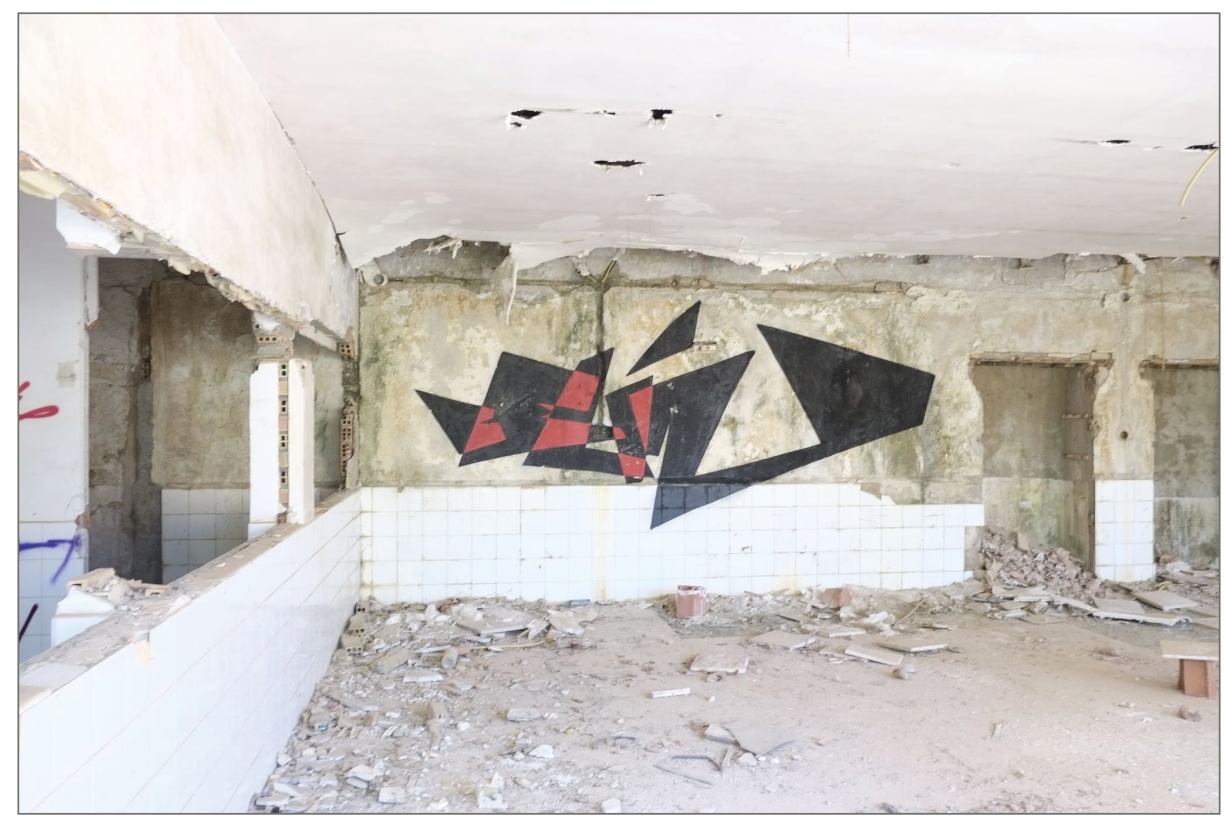

Figura 3. Grafiti de Belin. Fuente: imagen propia. 


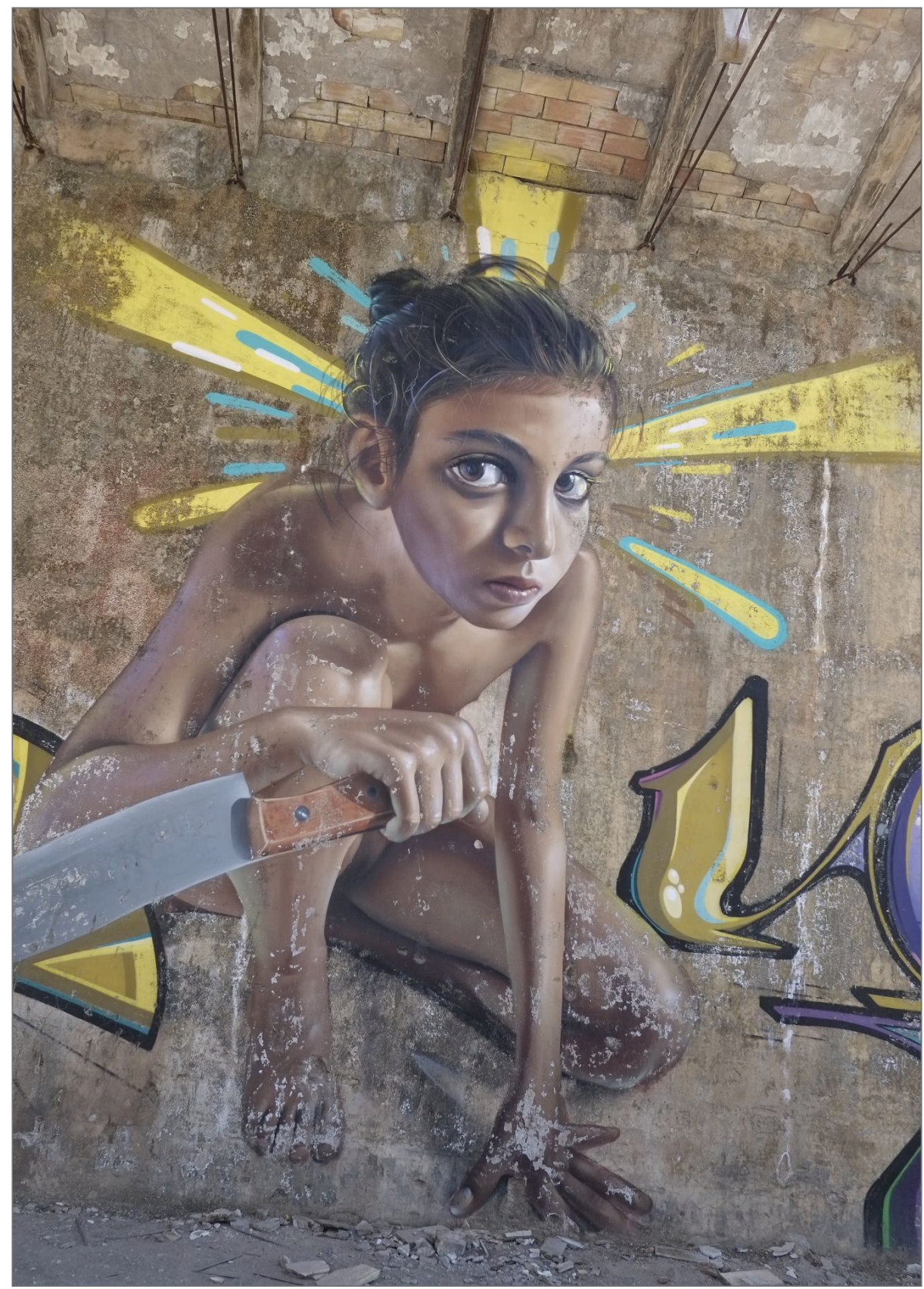

Figura 4. Obra de Belin en el estilo hiperrealista surrealista de sus inicios. Fundición La Cruz (Linares). Fuente: imagen propia. 


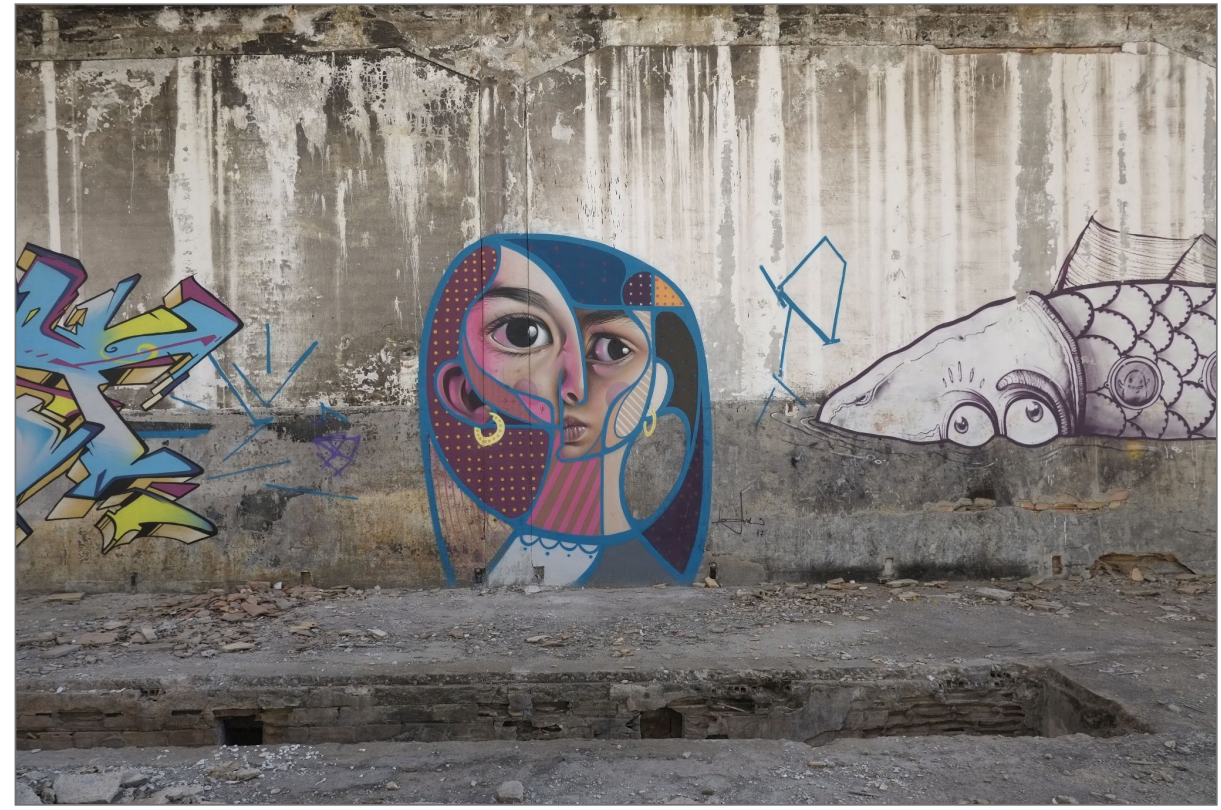

Figura 5. Obra de estilo hiperrealista neocubista del artista Belin. Fundición La Cruz (Linares). Fuente: imagen propia.

Aquí se ubicaría la estratigrafía del hall of fame en el que se han ido solapando obras que perdurarán únicamente a través de la documentación de las mismas. Este tipo de iniciativas artísticas como medio de revalorización de áreas en mal estado o poco transitadas, tienen aspectos muy positivos para la comunidad, especialmente puede ser interesante la atracción de turismo para un área deprimida económicamente y sufre una enorme despoblación, pero, por otro lado, se debe actuar con precaución para evitar sobreexplotarlas y producir efectos contrarios y rechazo por parte de la población, que debe integrarse en el proceso e identificarse con el espacio (Sarmento 2020).

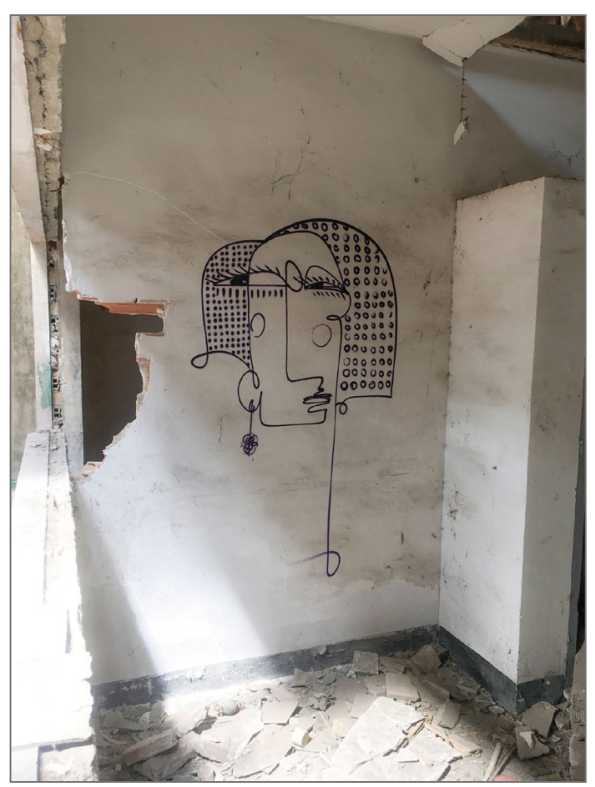

Figura 6. Retrato cubista de un solo trazo y color del artista Belin. Fundición La Cruz (Linares). Fuente: imagen propia. 
En cuanto a las posibilidades que nos brinda la documentación para el conocimiento de la evolución de los muros que conforman este hall of fame, cabría la posibilidad de elaborar un videomapping que se podría proyectar sobre el propio muro. En este sentido, como ya hemos referido, estaría la idea o el concepto de la conformación de una estratigrafía urbana cambiante y documentada. El uso del videomapping en el arte está bastante extendido, como por ejemplo para la difusión del patrimonio o la conmemoración de alguna fecha con proyección de imágenes en las fachadas de edificios, para la reproducción de policromías previas como en la iglesia de Sant Climent de Taüll de Lleida (Arquipa 2014), o para creación artística como Moving Mural${ }^{\beta}$. En este caso se realizaría un vídeo con las imágenes que se hayan tomado de las distintas obras para luego proyectarlas sobre el mismo espacio que ocuparon. De esta forma se puede conocer la realidad cambiante de estos muros, conservar la memoria colectiva y convertirlo en un revulsivo para la zona. Esta idea, presentada en un plano teórico, podría llevarse a cabo con una inversión institucional que conllevaría la adecuación de los accesos, pero debería ser puntual, para que la mayor parte del tiempo el espacio continúe desértico y por lo tanto apto para seguir siendo intervenido de forma espontánea por los artistas urbanos de la zona.

\section{PROPUESTA DE INTERVENCIÓN EN UN CASO DE ESPECIAL SIGNIFICACIÓN}

El arte urbano, en algunos casos, e incluso el grafiti como el caso de Muelle antes expuesto, pueden en algún momento ser susceptibles de patrimonializarse a través de la voluntad social y de normativas que permitieran su protección jurídica. Esa voluntad social se puede traducir en que la obra tenga una especial significación, es decir, que adquiera valores particulares, que vengan dados por la comunidad fundamentalmente y que tengan que ver con el contexto urbano en que se integra, contexto socio-político, histórico en definitiva. Serían obras que hayan producido un alto nivel de identidad en su comunidad (Luque 2019), símbolo de una época, de un hecho concreto de gran relevancia, etc. Es un factor de difícil medición en el que aún se está trabajando, más complejo quizá que para otro tipo de patrimonio puesto que está a caballo entre lo material y lo inmaterial (Luque \& Moral 2021). 


\subsection{Propuesta sobre la obra de Belin en Linares}

Como ejemplo de una obra que tiene especial significación dentro de su contexto de creación, se expone el caso de Belin (2021a) ${ }^{9}$ para la provincia de Jaén y en concreto en Linares. Su nombre se conoce y ha provocado identidad, respeto y cariño en su ciudad y provincia, teniendo gran éxito su primer estilo hiperrealista-surrealista. Posteriormente, alcanzó fama internacional con su estilo hiperrealista neocubista llevando la ciudad de Linares al resto del mundo, ciudad a la que sigue ligado y en la que se conservan sus obras (Almansa, Quiroga \& Luque 2014). Incluso aparece en un videoclip de Raphael, aunando los dos grandes nombres de la tierra. Aunque aún es joven y está en pleno proceso de desarrollo artístico, cuenta con una gran trayectoria, lo que se traduce en iniciativas para la gestión y documentación de su obra (Almansa, Quiroga \& Luque 2014). De hecho su obra está ya en galerías como Durán ${ }^{10}$ y el artista incluso ha salido en programas de televisión como El Hormiguero ${ }^{11}$.

La propuesta de intervención recae sobre un conjunto de tres obras representativas de su primer periodo que se encuentran en la Calle Zambrana de Linares. Esta céntrica calle cuenta con otras obras en los alrededores de artistas como Den XL y colaboraciones de Belin con Ana Karina Cruz Mavil, entre otros. A su vez, es una calle cercana a la de la casa del artista Belin, la cual presenta en su fachada obras que van cambiando con el tiempo.

Volviendo a la selección, tenemos, en primer lugar, la obra de Belin y Myrhwan de estilo realista que muestra a Venus recostada de espaldas al espectador observándose en un espejo que está sostenido por un demonio, licencia del autor para transformar la obra original de la Venus del espejo de Velázquez. Se observa al fondo un cortinaje rojo y un marco marrón sobre fondo gris en el que se ubica un hombre sentado en la acera pidiendo a los viandantes (Fig. 7). Presenta un buen estado de conservación, exceptuando algunas intervenciones pictóricas en azul y desprendimientos de parte de los morteros de las juntas de los bloques de hormigón, lo que ha supuesto la pérdida de capa pictórica en diversos puntos. También se observa vegetación en la zona inferior y acumulación de suciedad y depósitos, tal y como se registra en el mapa de alteraciones (Fig. 8). 


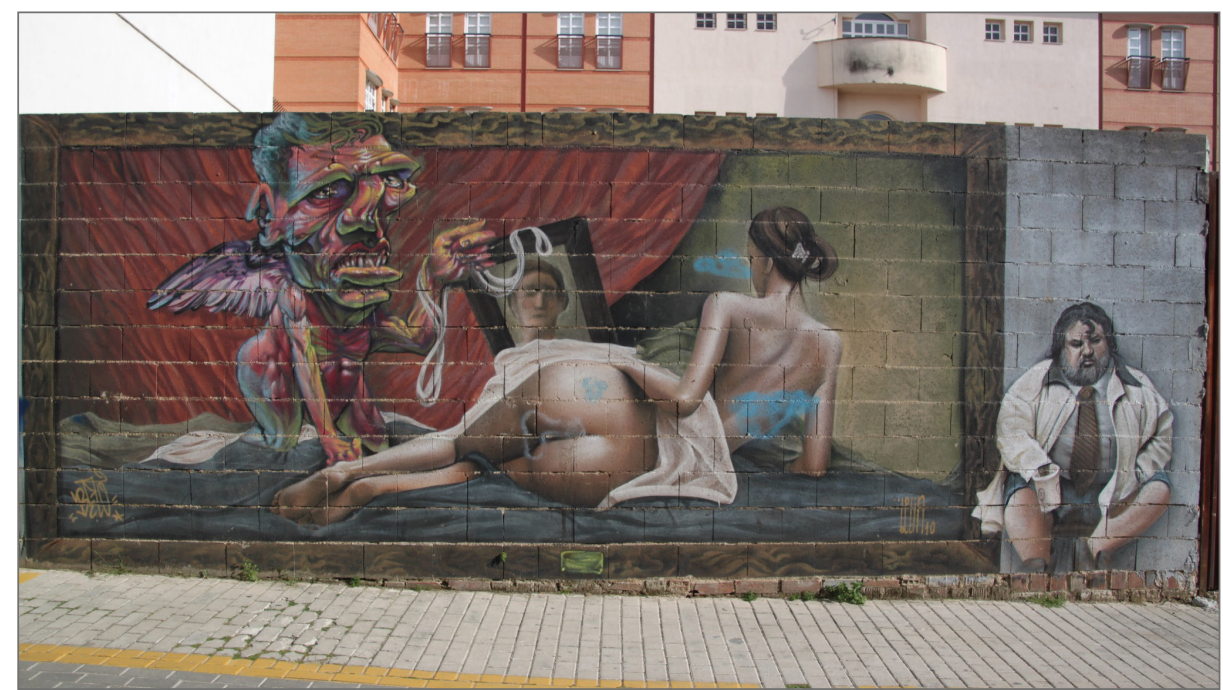

Figura 7. Obra de arte urbano de Belin y Myrhwan en la Calle Zambrana, Linares. (Fotografía: Rafael Mantas)

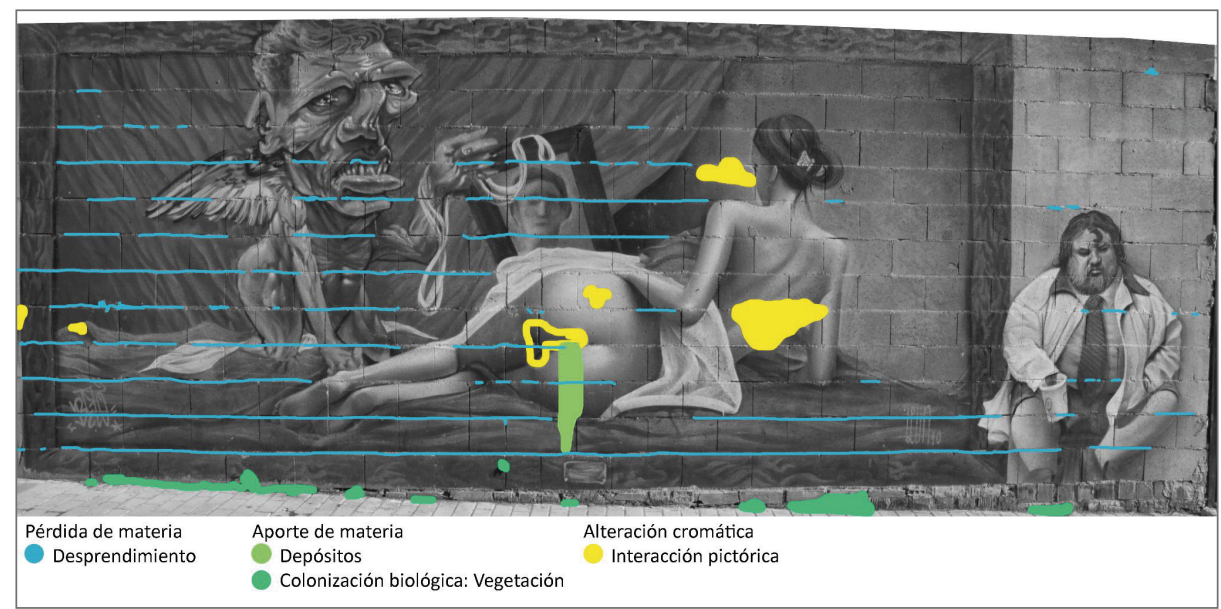

Figura 8. Mapa de alteraciones de la obra de Belin y Myrhwan de la Calle Zambrana (Linares). Fuente: elaboración propia.

La segunda obra es de estilo hiperrealista (Fig. 9), realizada por Belin en la que incluye un autorretrato del autor de medio cuerpo, con un casco de minero y una mochila en la que carga una cabria y una chimenea, haciendo alusión a la ciudad de Linares y a su historia minera, incluyendo además el nombre de la ciudad. La obra se encuentra en buen estado de conservación, aunque se aprecian zonas de coloración negra por colonización biológica en la zona 
superior y vegetación en la zona inferior, algunos desprendimientos en la zona inferior y grietas, datos que se recogen en el mapa de alteraciones (Fig. 10).

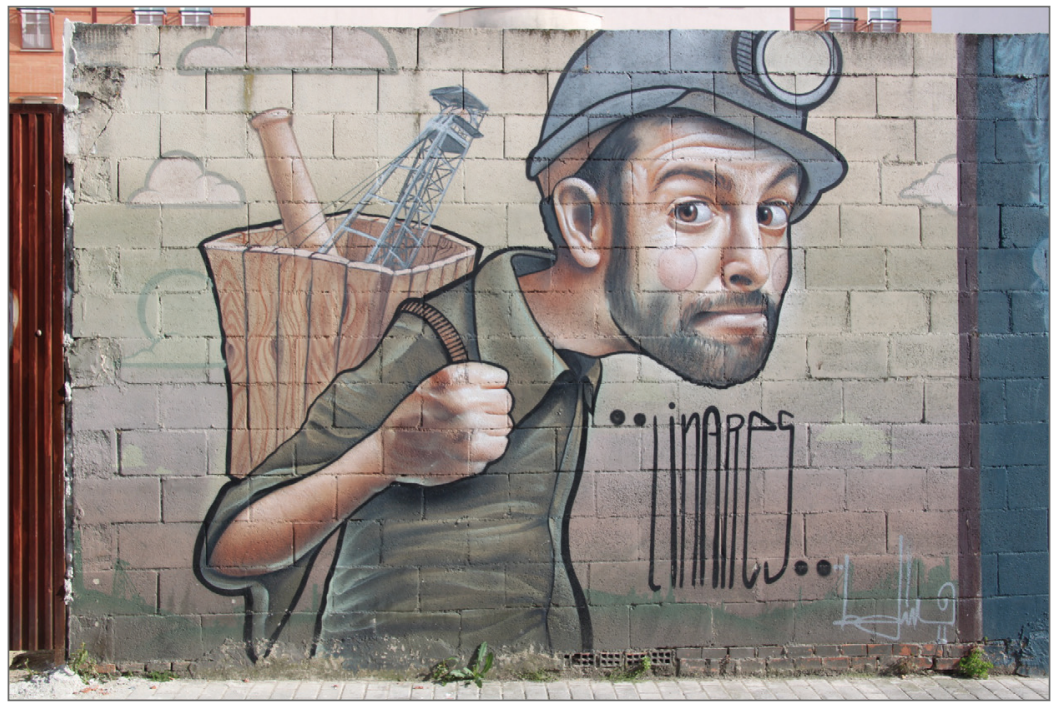

Figura 9. Obra de Belin en la que se autorretrata como un minero. Calle Zambrana, Linares (Fotografía Rafael Mantas)

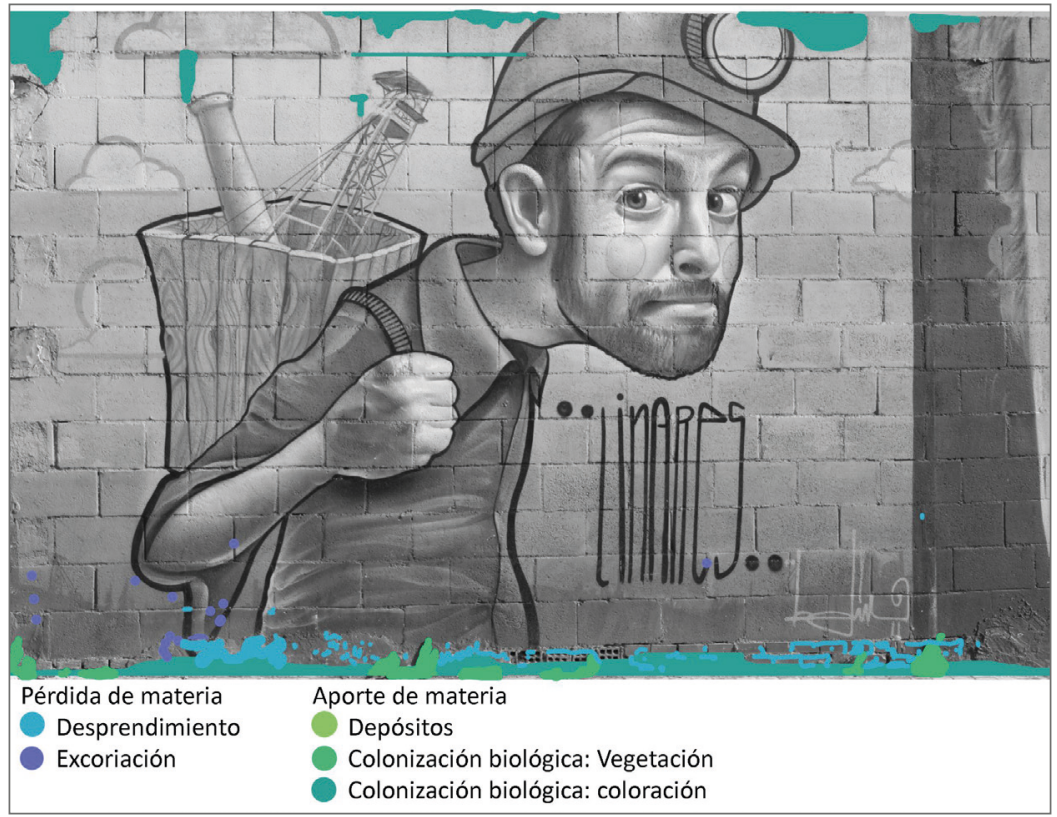

Figura 10. Mapa de alteraciones de la obra de Belin de la Calle Zambrana (Linares). Fuente: elaboración propia. 


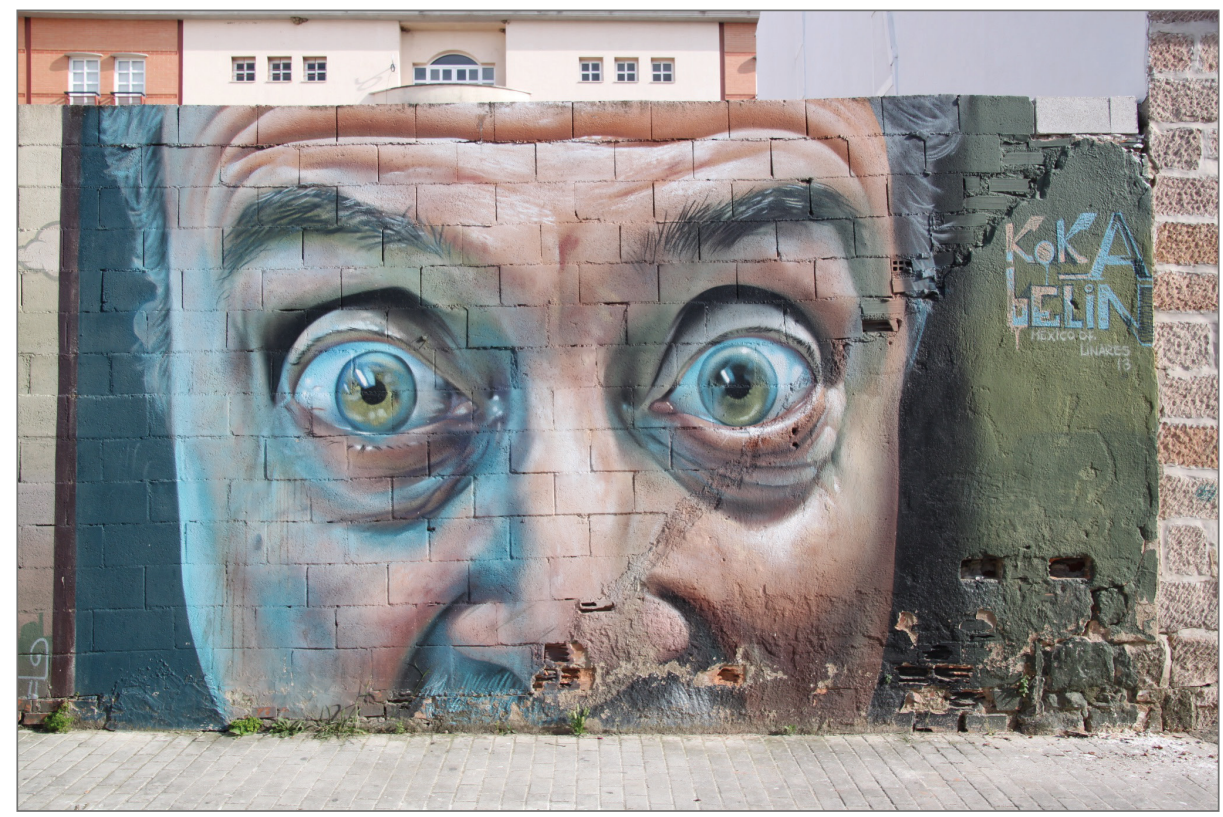

Figura 11. Obra de arte urbano de Belin y Koka en Calle Zambrana, Linares. (Fotografía Rafael Mantas)

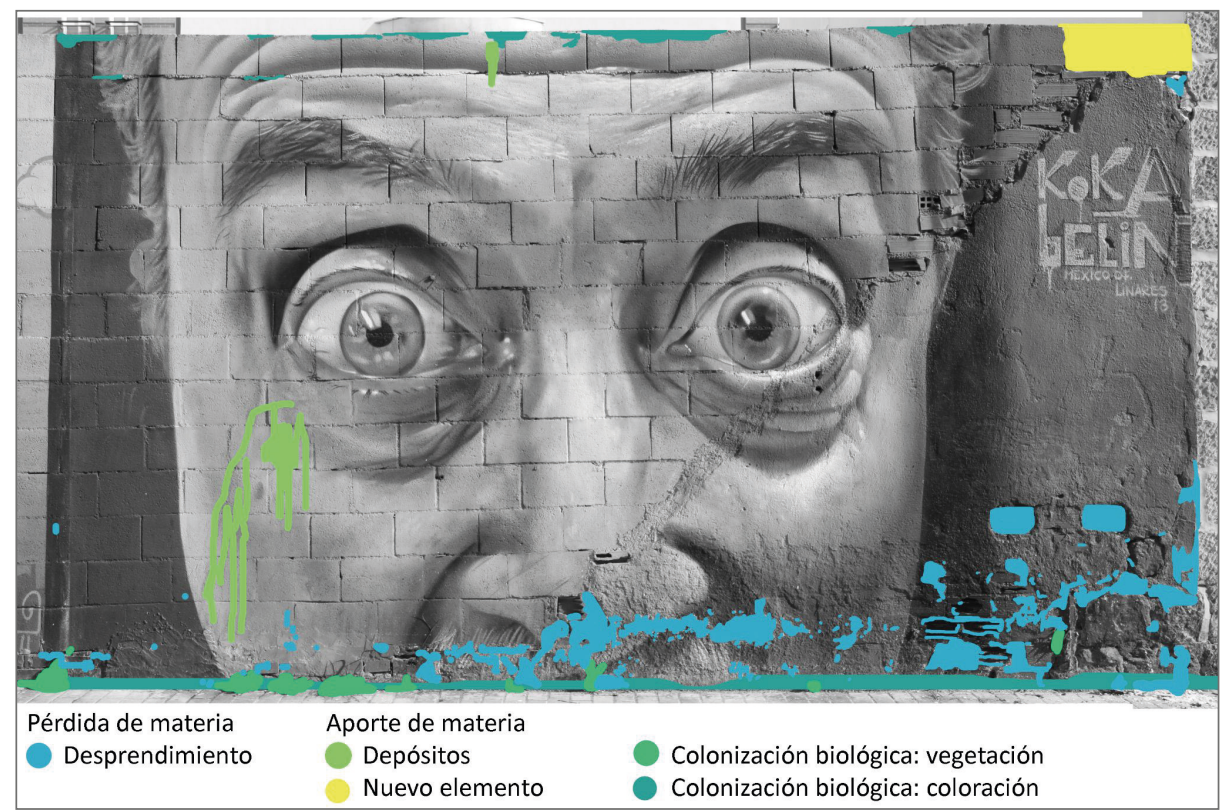

Figura 12. Mapa de alteraciones de la obra de Belin y Koka de la Calle Zambrana (Linares). Fuente: elaboración propia. 
La tercera obra, en colaboración con el artista Koka y de estilo hiperrealista, muestra un zoom en la zona de la mirada y la nariz de un personaje de cabello cano con los ojos abiertos de forma exagerada (Fig. 11). La obra se encuentra en proceso de deterioro principalmente en su zona inferior, en la que el soporte ha sufrido pérdidas de volumen considerables y desprendimientos de la capa pictórica por falta de adhesión al soporte de los morteros. También se observa colonización biológica que ha producido coloración negra en la zona superior y de vegetación en la inferior (Fig. 12).

Como propuesta de intervención se actuaría de forma similar en las tres obras. Inicialmente, una limpieza de la colonización biológica, la eliminación de los distintos depósitos de suciedad, manchas de diversa procedencia e interacciones pictóricas. Posteriormente, en aquellas zonas en las que se hayan producido disgregaciones, desprendimientos y excoriaciones se procederá a consolidar y fijar el soporte y a recuperar el volumen perdido con morteros que permitan la transpiración del muro. Tras este proceso se realizará una reintegración cromática de las superficies. Esta propuesta pretende ser de mínima intervención, buscando alargar la estabilidad de las obras por tener una especial significación para la comunidad, como se ha reseñado previamente. No obstante, el propio artista no lo considera adecuado. En una entrevista donde confiesa que si bien al inicio de su carrera no pensaba en la perdurabilidad de las obras "actualmente, sí pienso en que cuando voy a pintar un muro entre una base buena y firme, para que dure mucho tiempo"12, prefiere que sus obras no sean restauradas: "en mi caso pues sí, quiero que se conserve mi obra pero no me gustaría restaurar mi obra y menos que alguien más lo haga, ¿Quién sabría restaurar mi obra? ¿pintar como yo?"13. Estas declaraciones, que se repiten constantemente en numerosos artistas, evidencian la necesidad de que la profesión de restaurador se reivindique y cómo debe dar a conocer su labor. No obstante, muchos artistas prefieren intervenir ellos mismos su obra, como confirmó Coché Tomé en una entrevista inédita realizada en julio de 2021 o, incluso, desean que el tiempo forme parte de la obra, así lo expresó Ampparito en el I Simposio Internacional Reflejos del Arte Urbano, celebrado en $2020^{14}$. En el caso de Belin, sí que considera una buena idea la conservación no material de las obras: "me parece muy buena idea, creo que todo lo que sea conservar, proteger y difundir el arte, en este caso urbano suma y contribuye con la cultura de un pueblo, de una ciudad de un lugar, así que estoy de acuerdo, y hasta obligatorio cubrir con un video mapping"15. 


\section{CONCLUSIONES}

A lo largo de esta propuesta se ha podido comprobar que la conservación de obras de arte urbano y público y grafiti puede ser compleja y que, en muchas ocasiones, tan solo permiten por su propia concepción efímera, una documentación fiel y elaborada por profesionales que procuren su perdurabilidad para investigaciones futuras. Sin embargo, es posible alargar la vida de estas obras ya sea de forma no material, a través de la documentación, o material, con pequeñas intervenciones, de manera que se brinde la oportunidad a la comunidad de seguir haciendo suyas dichas manifestaciones como riqueza cultural de su entorno y representación de su día a día.

\section{Referencias bibliográficas}

Almansa Moreno, José Manuel, María Victoria Quirosa García \& Laura Luque Rodrigo. 2014. "La vulnerabilidad del grafiti: Los nuevos retos del siglo XXI". En Conservación de Arte Contemporáneo: $15^{a}$ jornada, organiza, Museo Nacional Centro de Arte Reina Sofía, 65-80. Madrid: MNCARS

Almirón Casado, Víctor. 2021. "Arqueología del grafiti: Estratos del lienzo urbano". PH 103: 2157. https://doi.org/10.33349/2021.103.4939

Arquipa. 2014. "El mapping como herramienta de difusión del patrimonio". Arquitectura y Patrimonio [web personal], 21 oct. https://arquipa.wordpress.com/2014/10/21/el-mapping-como-herramienta-de-difusion-del-patrimonio/

Bengtsen, Peter. 2021. "Approaches to documenting and preserving graffiti and street art". Keynote lecture, Conference: FORM(AT): Documenting, Collecting and Archiving Street Art. Liubliana Vídeo de Youtube, 55:25, 29 jun. https://www.youtube.com/watch?v=5GE1UK8q9go

Delgado Chica, Francisco. 2021. "Dilemas del arte urbano como patrimonio: La figura de Belin en Jaén y el paso de la calle al museo". PH 103:136-8. https://doi. org/10.33349/2021.103.4877.

Figueroa Saavedra, Fernando. 2021. Graphitfragen: Una mirada reflexiva sobre el graffiti. Madrid: Minotauro

García Gayo, Elena \& Laura Luque Rodrigo, coords. 2021. "Dilemas del arte urbano como patrimonio". PH 103: 106-223. https://doi.org/10.33349/2021.103

García Gayo, Elena et al. 2016. "Propuesta de código deontológico para la conservación y restauración de arte urbano". Ge-Conservación 10: 186-92. https://doi.org/10.37558/gec. v10i0.419

García Gayo, Elena, Laura Luque Rodrigo \& Adris Díaz Fernández, coords. 2021. Reflejos del arte urbano. Monterrey, México: Universidad Autónoma de Nuevo León 
García Gayo, Elena. 2017. "Restauración del Muelle de Montera: Gestión, innovación y riesgos". En Conservación de Arte Contemporáneo: $15^{a}$ jornada, organiza, Museo Nacional Centro de Arte Reina Sofía, 167-77. Madrid: MNCARS

ICOMOS-ISCS (International Council on Monuments and Sites-International Scientific Committee for Stone). 2008. Illustrated glossary on stone deterioration patterns [Glossaire illustré sur les formes d'altération de la pierre]. Contributors, Tamara Anson Cartwright et al.; ed., Veronique Vergès-Belmin. París: ICOMOS

Luque Rodrigo, Laura \& Carmen Moral Ruiz. 2021. "El arte urbano como patrimonio inmaterial. Posibilidades para su protección y difusión". En Actas del I Simposio anual de Patrimonio Natural y Cultural ICOMOS España: 21, 22 y 23 de noviembre 2019 Madrid, José Luis Lerma García, Víctor Manuel López-Menchero Bendicho \& Alfonso Maldonado Zamora Valencia, eds., 57-64. València: Universitat Politècnica de València. http://hdl.handle. net/10251/160166

Luque Rodrigo, Laura. 2015. "Reflexiones en torno a una obra tan legal como ilegal". Mural Street Art Conservation 2: 20-1

Luque Rodrigo, Laura. 2019. "Identidad e imagen de la ciudad contemporánea: los museos de arte urbano". Ge-Conservación 16: 176-85. https://doi.org/10.37558/gec.v16i0.706

Moral Ruiz, Carmen \& Laura Luque Rodrigo. 2021. "Técnicas de investigación y catalogación del arte urbano desde la transdisciplinariedad: Aplicaciones y retos de futuro". En Actas del I Simposio anual de Patrimonio Natural y Cultural ICOMOS España: 21, 22 y 23 de noviembre 2019 Madrid, José Luis Lerma García, Víctor Manuel López-Menchero Bendicho \& Alfonso Maldonado Zamora Valencia, eds., 73-81. València: Universitat Politècnica de València. http://hdl.handle.net/10251/160178

Pérez Plaza, Arturo, coord. 2008. El paisaje industrial en Andalucía: Jornadas Europeas de Patrimonio 2008. Sevilla: Consejería de Cultura

Rava, Antonio \& Alessandra Collina. 2018. "Introduzione: Ragioni per la conservazione della Street Art". Kermes 109: 17-9

Sarmento, Clara. 2020. "Methodological proposals and critical responses for the study of graffiti and street art". SAUC - Street Art and Urban Creativity, 6(2): 24-47. https://doi. org/10.25765/sauc.v6i2.240

Úbeda García, María Isabel. 2016. "Propuesta de un modelo de registro para el análisis y documentación de obras de arte urbano". Ge-Conservacion 10: 169-79. https://doi. org/10.37558/gec.v10i0.410

\section{Notas}

${ }^{1}$ El uso que se hace del término graffiti, como anglicismo, es en referencia al movimiento, mientras que cuando nos referimos a obras concretas se emplea la forma española grafiti. Este uso es el que se utiliza en las últimas publicaciones científicas sobre el tema, especialmente las del Grupo de Arte Urbano y Público del GEIIC, constatable en sus monográficos en la revista Ge-Conservación (2016 y 2019), debate en la Revista PH (García \& Luque 2021), el reciente libro Reflejos de arte urbano (García, Luque \& Díaz 2021) y otras tantas publicaciones.

${ }^{2}$ El asunto del arte urbano y el muralismo público y su conservación es una cuestión compleja y que debe tratarse a fondo, con objeto de no exceder la extensión del texto y no perder de 
vista el discurso central del mismo, se recomiendan las siguientes referencias para ahondar en el tema: García \& Luque 2021; revista Ge-conservación 2016 y 2019; Figueroa 2021 y Urbanario, web personal de Javier Abarca: https://urbanario.es/articulos/.

3 “BIComun ThinkCommons (03) \#BICommons". Niquelarte 2013. http://niquelarte.bicomun.org/ es/bicomun-thinkcommons-03-bicommons-2/

4 "Proyecto Coremans", Monografías del IPCE-Instituto del Patrimonio Cultural de España. https://ipce.culturaydeporte.gob.es/difusion/publicaciones/libros-del-ipce/coremans.html

${ }^{5}$ CAPuS Project (Project Conservation of Art in Public Spaces). Glossary. http://www.capusproject.eu/glossary/

${ }^{6}$ Street Art Belgrade 2021. Take III: Loving Street Art Belgrade https://vrallart.com/vr-exhibitions/eg/take_3_street_art_belgrade/

7 "Arte urbano y museo: Competencias e (in)compatibilidades". Número monográfico Ge-Conservación 16: 120-325. 2019. https://doi.org/10.37558/gec.v16i0.730

${ }^{8}$ Moving Mural ¿Qué haremos con lo que sabemos? (2011) Dirección, Fernando Pérez. IMVGItinerario Muralístico de Vitoria-Gasteiz. http://www.muralismopublico.com/p/es/murales/ vitoria-gasteiz/que-haremos-con-lo-que-sabemos-moving-mural-2011/moving-mural.php

${ }^{9}$ Belin, página personal del artista: https://www.belin.es/. Para más información del autor: 1) Delgado (2021) 2) Luque (2015). 3) búsqueda 'Belin' en la hemeroteca digital de Diario Ideal: https://www.ideal.es/hemeroteca/belin.html; 4) ídem en el diario Jaén.

${ }^{10}$ Duran Online Gallery. https://www.durangallery.com/belin.html

11 "Un reto imposible y un regalo muy especial, Sebastián Yatra se deja llevar por las Twin Melody y Pablo Motos". El Hormiguero, emitido en Antena3, 24 jun 2021. https://www. antena3.com/programas/el-hormiguero/secciones/twin-melody/reto-imposible-regalo-muy-especial-sebastian-yatra-deja-llevar_2021062460d4f007ba65dd000141bccd.html

${ }^{12}$ Entrevista realizada virtualmente en septiembre de 2021, registrada textualmente

${ }^{13}$ Entrevista realizada virtualmente en septiembre de 2021, registrada textualmente

${ }^{14}$ Mesa redonda participativa: ¿A dónde vamos? De la calle a la virtualidad. Moderan: Miguel Ángel Moreno Carretero (artista y gestor cultural) y Ampparito (artista), en el I Simposio Internacional Reflejos del Arte Urbano, Grupo de Arte Urbano y Público del Ge-IIC, Universidad de Jaén y Universidad de Monterrey, 17 de septiembre de 2020

${ }^{15}$ Entrevista realizada virtualmente en septiembre de 2021, registrada textualmente.

(Artículo recibido: 24-09-21; aceptado: 15-11-21) 